\title{
Epstein-Barr Virus-Associated Myoid Tumors in Human Immunodeficiency Virus-Infected Patients
}

\author{
Khaba MC1, Ramdial PK ${ }^{1 *}$, Pillay $\mathbf{B}^{2}$, Steyn $\mathbf{A J}^{3,4}$ and Nargan $\mathrm{K}^{3}$
}

${ }^{1}$ Department of Anatomical Pathology, National Health Laboratory Service \& School of Laboratory Medicine and Medical Sciences, University of KwaZulu-Natal, KwaZulu-Natal, South Africa

${ }^{2}$ Department of Vascular/Endovascular Surgery, Nelson R Mandela School of Medicine, University of KwaZulu-Natal, KwaZulu-Natal, South Africa

${ }^{3}$ KwaZulu-Natal Research Institute for Tuberculosis and HIV, KwaZulu-Natal, South Africa

${ }^{4}$ Department of Microbiology and Centers for AIDS Research and Free Radical Biology, University of Alabama at Birmingham, Alabama, USA

\begin{abstract}
Although Epstein Barr Virus (EBV)-associated myoid tumors (EBV-MTs) are a well-recognized entity, commonly associated with immunocompromise and immunosuppression, including Human Immunodeficiency Virus (HIV) infection and acquired immunodeficiency syndrome (AIDS), they are reported uncommonly. An expanding spectrum of EBV-MTs has emerged in the last decade, associated with an increasing range of organ involvement. EBV-MTs are associated with diagnostic pitfalls, incomplete etiopathogenetic understanding and treatment challenges. This review revisits EBV-MTs in the HIV and AIDS setting. The characteristics of EBV, their etiopathogenetic role in neoplasia, in general and in HIV-associated EBV-MTs in particular, are discussed. Historical, demographic and diagnostic clinicopathological features of EBV-MTs are detailed, classification and diagnostic challenges are emphasized, treatment options and dilemmas are presented briefly and outcome-associated factors are described. While attention is drawn to current demographic, classification, etiopathogenetic and management uncertainties and hiatuses, potential future approaches to address these shortcomings are also alluded to.
\end{abstract}

Keywords: HIV; AIDS; EBV; Myoid tumors; Leiomyomas; Myopericytomas; Leiomyosarcoma

\section{Introduction}

Human immunodeficiency virus (HIV) infection is associated with a heightened risk of specific cancer types, labeled "Acquired immunodeficiency syndrome (AIDS)-defining cancers" [1]. These include Kaposi sarcoma, systemic non-Hodgkin lymphoma/primary central nervous system lymphoma and invasive cervical cancer, that are pathogenetically linked to Human herpes virus 8 (HHV8), Epstein Barr virus (EBV) and Human papilloma virus (HPV), respectively [2]. More effective and better tolerated highly active anti-retroviral therapy (HAART) is not only responsible for improved longevity of HIVinfected patients, but also for the number of non-AIDS-defining cancers (NADCs) surpassing that of AIDS-defining cancers $[1,2]$. Some of the malignancies that have increased in HIV-infected individuals include Hodgkin lymphoma, lung and anogenital cancers, multiple myeloma and central nervous system malignant tumors [1]. Pulmonary, anal and colorectal tumors present at a younger mean age, have more advanced disease and poorer outcomes than those in their HIV-uninfected counterparts. The pathogenesis of NADCs is multifactorial but most are characterized by a strong viral pathogenetic link. Oral and anal squamous, Merkel and hepatocellular carcinomas are associated with $\mathrm{HPV}$, polyoma and hepatitis $\mathrm{B} / \mathrm{C}$ virus infections, respectively. Among the non-epithelial NADCs, Hodgkin lymphoma and EBV myoid tumors are associated with EBV infection [2].

EBV-associated myoid tumors (EBV-MTs) are a wellrecognized entity, strongly associated with immunocompromise and immunosuppression, including post-transplant states, common variable immunodeficiency syndrome, glucocorticoid and tumor necrosis factor administration and HIV infection [3]. Since the first description of HIV-associated smooth muscle tumors (HIV-SMTs) in 1990 [4], an increasing spectrum of HIV-associated myoid tumors (HIV-MTs) with an expanding repertoire of organ involvement has been documented $[5,6]$. While the heightened awareness, diagnostic technological advancements and evolving understanding of EBVMTs have improved their diagnostic recognition, EBV-MTs remain enshrouded by etiopathogenetic hiatuses, clinicopathological diagnostic challenges and incomplete treatment guidelines.

This review revisits EBV-MTs in the context of HIV and AIDS. In so doing, historical, demographic and diagnostic histopathological features are described, etiopathogenetic mechanisms and diagnostic challenges are highlighted, treatment options and dilemmas are presented briefly and outcome-associated factors are discussed. Uncertainties and gaps on the entity are tabled and potential practical suggestions to limit these shortcomings are tendered.

\section{History of Myoid Tumors in Patients with HIV Infection/AIDS}

Although Chadwick [4] is accredited with the description of the first childhood leiomyoma in 1990, it was van Hoeven [7] in 1993, who re-appraised a hepatic fibrosarcoma diagnosed approximately 8 years earlier [8], and not only re-diagnosed it as a smooth muscle tumor, but also confirmed an EBV signature therein. This revised diagnosis marked the emergence of the first EBV-associated SMT (EBV-SMT) in the HIV context [7]. The recognition of smooth muscle tumors (SMTs) in the HIV/AIDS context was an extension

*Corresponding author: PK Ramdial, Department of Anatomical Pathology, Leve 3, Laboratory Building, Inkosi Albert Luthuli Central Hospital, 800 Vusi Mzimela Road, Mayville, 4058, KwaZulu-Natal, South Africa; Tel: +27 (0)31 2402693; Fax: +27(0)31 2402610; E-mail: ramdialpk@gmail.com

Received July 30, 2016; Accepted August 30, 2016; Published September 06 2016

Citation: Khaba MC, Ramdial PK, Pillay B, Steyn AJ, Nargan K (2016) Epstein-Barr Virus-Associated Myoid Tumors in Human Immunodeficiency Virus-Infected Patients. J AIDS Clin Res 7: 616. doi:10.4172/2155-6113.1000616

Copyright: ( $) 2016$ Khaba MC, et al. This is an open-access article distributed unde the terms of the Creative Commons Attribution License, which permits unrestricted use, distribution, and reproduction in any medium, provided the original author and source are credited. 
of their recognition in the setting of immunosuppression, initially in transplant recipients and congenital immunodeficiency syndromes. Whilst the first adult HIV-SMT was diagnosed in 1992 [9] and the association with EBV was noted in 1994 [3], the majority of afflicted patients were children [10]. The literature of the 1900s highlighted the occurrence in multifocal and unusual anatomical sites [4,7,11-24]. The former was plagued by the issue of multicentricity versus multiple metastases $[16,21]$. There was continued global debate on these themes at the turn of the century [25-33]. Additionally, and moreso between 2005 to 2010, debate on optimal classification systems [34-39] and the role of EBV pathogenetic mechanisms in HIV-associated EBV-MTs increased [18,27,30,34-44]. Whilst some workers used conventional criteria to grade and classify the SMTs, others proposed use of the generic term, 'smooth muscle tumor' rather than classification into benign, malignant and uncertain malignant potential tumors. In this time period, the role of chemoradiation for tumor shrinkage was also reported [36]. The next milestone in the evolution of AIDS-MTs was the expansion of the repertoire of EBV-MTs to include EBV-associated myopericytomas (EBV-MPCTs). Whilst the architectural patterns and cytomorphological features of smooth muscle and myopericytic tumors overlapped, the immunophenotypic features revealed desmin immunonegativity and $\mathrm{H}$-caldesmon immunopositivity in the latter [45,46]. EBV-MPCTs encompassed benign and malignant forms, the latter characterized by a spectrum of atypia, as typified by the relatively recently documented conventional malignant myopericytoma classification criteria [47].

Despite the increasing incidence of AIDS in the developing world [48], the reported number of EBV-MTs has not shown a parallel increase in the $21^{\text {st }}$ century. Whether this is a true plateau as a consequence of improved management of AIDS-associated diseases worldwide or whether this is an under-reporting phenomenon are uncertain. Recent South African input has highlighted an expanding clinicopathological profile of EBV-MTs [48-50] and also introduced hybrid or mixed EBVSMTs and MPCTs with dual EBV effects on vascular smooth muscle cells and myopericytes [50].

\section{Pathogenesis of EBV-MTs}

An understanding of the pathogenesis of EBV-MTs requires comprehension of the complex EBV attributes that facilitate lytic or latent viral infection and associated cell replication and transformation.

\section{EBV: General Features and Viral Attributes}

Since the discovery of EBV in cell cultures of African Burkitt lymphoma, it has been increasingly recognized that EBV infects humans readily, establishes life-long infective latency and is associated with a range of neoplastic and non-neoplastic pathology [51]. While EBV was classified as a tumor virus by the World Health Organization in 1997 [52], a distinctive role for EBV in tumorigenesis requires pathogenetic evidence because of its ubiquitousness. EBV is a linear, double-stranded DNA virus, a member of the $\gamma$-subfamily of herpes virus [27]. While structurally composed of $>85$ genes [53], a minority are associated with transformation and replication (Table 1). Two EBV subtypes, EBV-1 and EBV-2, are known to infect humans; these are identified by organization and polymorphisms of Epstein Barr nuclear antigen (EBNA) genes 2, 3A, 3B and 3C [31]. EBV-1 is more common in most populations while EBV-2 is increased in malaria-endemic zones and in immunocompromized states [31,53].

1. Raised EBV antibody titres prior to tumor development

2. Presence of EBV genome in neoplastic but not in associated/ adjacent non-neoplastic cells

3. Viral genome clonality

4. Expression of viral genes in neoplastic cells

\section{B. EBV products and functions}

EBNA-1

- $\quad$ Sequence-specific DNA-binding phosphoprotein

- Replication/maintenance of EBV genome

- Maintains EBV latency

- Transcriptional co-activation and cell immortalisation

EBNA-2

- Coordinates viral gene expression in latency III

- Transactivates many cell genes

EBNA-3A

EBNA-3B

EBNA-3C

EBNA-LP (EBNA-5)

- Transcriptional regulators

- Crucial for in vitro cell transformation

- Transcriptional regulator but dispensable

- Drives resting B-lymphocytes into $\mathrm{G}_{1}$ of cell cycle

- Involved in Notch signalling pathway

LMP-1

- Facilitates transformation and cell growth

- Inhibits apoptosis by increasing bcl2 levels

LMP-2A

LMP-2B

- Maintenance of EBV latency

- Non-essential for transformation

EBER 1

- Sequence-specific DNA binding protein

- Maintenance/replication of EBV episome

- Transcriptional co-activator

EBER 2

- Upregulates viral and cellular genes for transformation

- Involved in Notch signalling pathway

Bam $H 1 A$ region

- May help maintain latency

- Interacts with cellular Notch

\section{EBV latency types and gene expression profiles}

\begin{tabular}{|l|l|}
\hline Latency Type & Viral Protein Expression Profile \\
\hline Type I Latency & EBER1, EBER2, EBNA-1 \\
\hline Type II Latency & EBER1, EBER2, EBNA-1, LMP-1, LMP-2, Bam H1A \\
\hline Type III Latency & EBER1, EBER2, EBNA-1, EBNA-2, EBNA-3, LMP-1, LMP-2 \\
\hline
\end{tabular}

Table 1: EBV: Pathogenetic evidence and latency types of EBV in tumorigenesis $[25,29,45,51]$. 
EBV is typified by lytic (replicative) and latent phases [29,34,51]. The former is episodic and typified by marked replication-dependent protein amplification of the EBV genome that is then assembled into virions (Figure 1); these are released following cell rupture [27]. Primary EBV infection occurs mainly in the orophrynx where lytic replication and release of viral progeny follows [6]. Most EBV resides in a latent state in quiescent B-lymphocytes [31]. Three latency classes of EBV exist that are characterized by distinctive but limited gene expression including 6 nuclear proteins (EBNAs), 3 membrane proteins (latent membrane proteins), EBV-encoded small rNAs (EBERs) and BamHI A region RNA transcripts (Table 1) [53]. Latent membrane proteins (LMPs) are integral membrane proteins $[27,31,53]$

Burkitt lymphoma is associated with a Type I latency profile while EBV-associated Hodgkin lymphoma, peripheral NK/Tcell lymphoma and undifferentiated nasopharyngeal catcinoma are characterized by Type II latency [27,31,51-53]. Although the exact latency profile of EBV-MTs is inconconclusive, current evidence points to Type III latency and a pathogenetic role for immunosuppression-related cytotoxic T-cells [27,34,51-53]. del-LMP1, a variant of the $L M P 1$ gene, associated with increased cell transformation potential and decreased immunogenicity, is typified by the deletion of 10 amino acids at the C-terminus in EBV-1 and EBV-2, albeit more commonly in EBV-2 [27]. CD21-mediated entry has been hypothesized as the main epithelial and mesenchymal cellular infective EBV mechanism $[18,51,54]$. In addition, two CD21-independent pathways have been proposed, including a secretory component-mediated IgA transport pathway and a cell-to-cell contact pathway, involving virus producers and epithelial cells [51].

\section{EBV and Myoid Tumors}

Immunosupression plays a key role in the pathogenesis of EBVMTs in general [55]. The mechanism of EBV entry into myoid cells is poorly understood. Although the CD21 expression by smooth muscle cells is weak, a role for CD21 or CD21 cross-reacting antibodies has been suggested [18,27]. It is controversial whether fusion of human embryonic fibroblasts and EBV-superinfected lymphoblastoid cells may be the portal of smooth muscle infection. Neither the mechanism of transformation, type of viral latency nor the determinants of immune modulation are known with certainty [33,34]. EBV-1, EBV-2 and varied chromosomal integration of EBV DNA [54] and del LMP1 variant are recognized in EBV-SMTs. Type III latency[27,54,56], typified by the full array of latency genes, including an EBNA-1, EBNA-2, EBNA-3A, EBNA-3B, EBNA-3C, LMP and EBER recognition profile and Type I latency [55,57] with EBNA1 and EBNA2 and undetectable LMP1, are documented. While $L M P 1$ has established transforming characteristics, its role in EBV-MT pathogenesis remains unclear because of equivocal immunostaining patterns [55].

Mammalian target of rapamycin (mTOR), activated by many growth factors and nutrients through various signalling pathways, plays a pivotal role in cell growth regulation, by stimulating protein synthesis [55,57]. Increased but dysregulated mTOR activity is associated with tumorigenesis. Recently, Ong et al. documented overactivation of Akt/ mTOR signaling in EBV-SMTs. Methylation of promoter regions, reflective of epigenetic alterations in cancers, have been implicated in EBV-associated tumorigenesis. Results of methylation profiling of tumor suppressor genes in EBV-SMTs are emerging. Ong et al. have reported consistent hypermethylation of ras association domain family 1A (RASSF1A: involved in microtubule stabilisation and mitotic regulation), variable promoter hypermethylation of retinoic receptor gene ( $R A R \beta$ : involved in cellular signalling, growth and differentiation), glutathione $S$-transferase (GSTP: for cell detoxification and protection from carcinogens), death-associated protein kinase (DAPK: Apoptosis mediator) and p14 (ARF: Cell cycle regulator), and hypomethylation

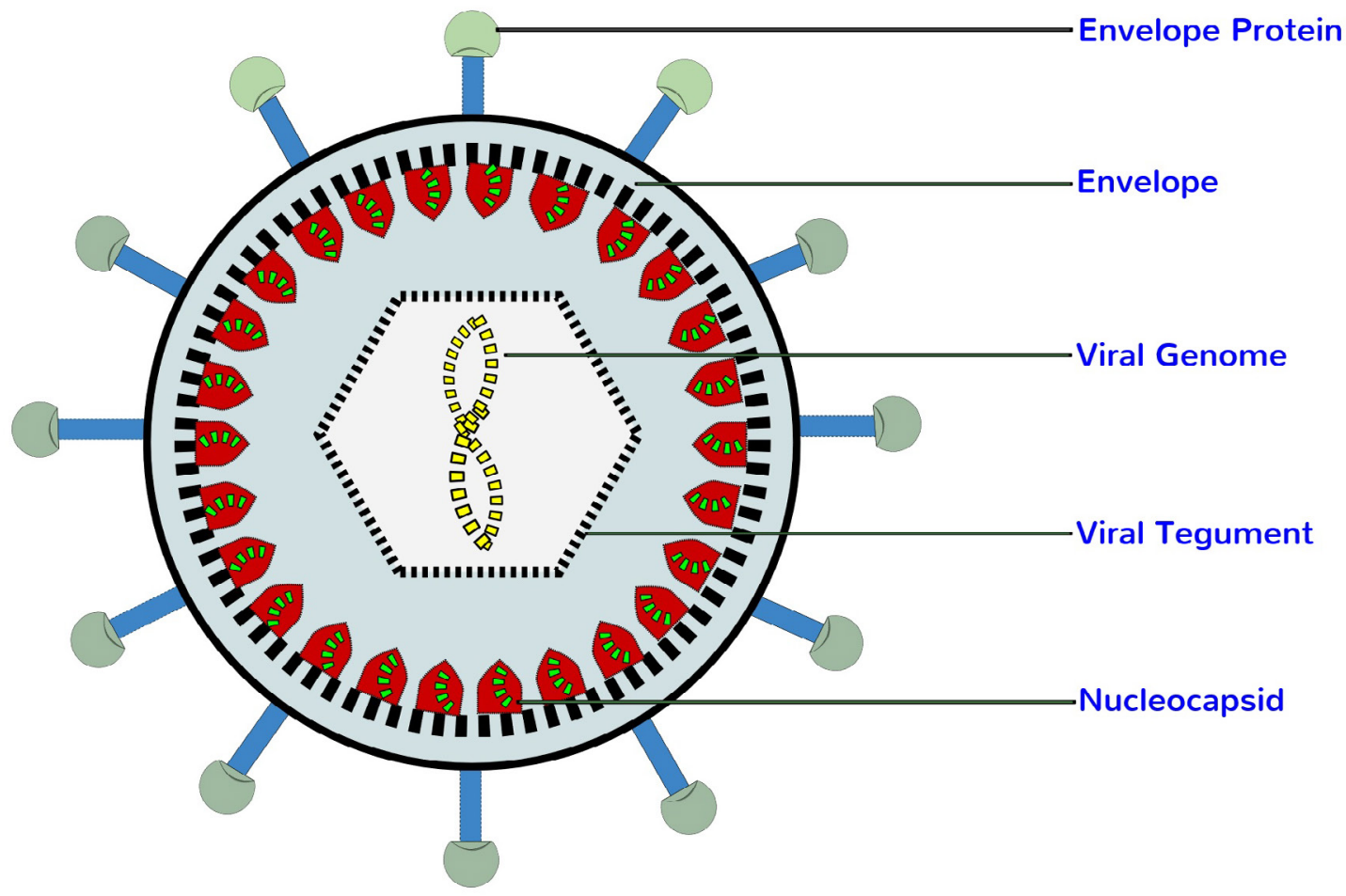

Figure 1: Annotated representation of the EBV virion. 
of O6-methylguanine-DNA methyl transferase (MGMT: Facilitator of DNA repair) [57].

EBV-MTs are characterized by multifocal visceral disease. It has been debated whether these are independent primary tumors or metastases from a single primary tumor. Tumoral Southern blot and microsatellite analyses have confirmed the former notion [18,42,54]. Additionally, real-time PCR analysis of the long terminal repeat regions of EBV in different EBV-MTs from the same patient have confirmed, in the majority of cases, that each tumor originated from separate clones of cells, indicating that multiple tumors are predominantly the result of independent EBV infective episodes [34].

Based on increased CD21 levels in EBV-MT cells in patients with AIDS than non-AIDS related SMTs, CD21 upregulation in EBV-MTs in patients with AIDS has been posited [18]. The inconsistent CD21 expression in EBV-MTs supports additional CD21-independent pathogenetic pathways and mechanisms, such as infection of smooth muscle cells by fusion with EBV-infected lymphocytes [6,27]. Furthermore, Bargiela et al. proposed that high viral titres during primary EBV infection in immunocompromised states promoted EBV infection of tissue not usually susceptible to EBV infection, including smooth muscle [12]. Furthermore, in the context of HIV/ AIDS immunosuppression, reactivation of EBV infection is enhanced during immunosuppression, particularly a decrease in T-suppressor lymphocytes. This may also promote dissemination of EBV to cells and tissue not normally infected by the virus. EBV-MTs occur in advanced stages of HIV/AIDS with CD4 counts usually $<100$ cells $/ \mathrm{mm}^{3}$ [26]; it is possible that the HIV/AIDS-associated declining T-lymphocyte population facilitates EBV-induced smooth muscle proliferation [55]. The time period between confirmatory HIV infection and clinical manifestation of EBV-SMTs spans 1 month to 18 years, with $>67 \%$ being diagnosed within 4 years of HIV confirmation [6]. An indirect role for chronic HIV infection in EBV-MT tumorigenesis has been purported based on defective HIV/AIDS associated immunosurveillance, chronic antigenic stimulation, the impact of multiple AIDS-associated comorbid infective agents and HIV-induced $\mathrm{T}$ cell-associated growth factor stimulation [11]. A direct oncogenic hit by HIV on stem cells in the pathogenesis of EBV-MTs remains unproven [9].

\section{Classification of EBV-MTs}

The classification of EBV-MTs has been challenged by criteria for malignancy, similar to that of conventional SMTs. Still germane to this difficulty are the organ-dependent defining features of malignancy in SMTs, and the added recognition that tumor outcome in HIV/AIDS patients is dictated by the immune status of the patient rather than the microscopic features of the tumor. Some workers have proposed the overarching term "EBV-associated smooth muscle tumor" rather than their categorization into benign and malignant tumors [34]. The rationale proffered is that the microscopic profile of the EBV-SMTs does not fit the existing criteria diagnostic of EBV-naïve leiomyoma or leiomyosarcoma [34,58]. Other workers have, however, recognized cellular pleomorphism, mitotic activity and necrosis in EBV-SMTs and have used compelling microscopic criteria, independent of outcome, to classify these tumors $[6,10,50]$. In 2008, the range of EBVMTs expanded to include EBV-MPCTs [59]. The histopathological spectrum of MPCTs in the general population has expanded relatively recently to include benign and malignant variants; the latter is based on microscopic criteria similar to that employed for SMTs $[49,50]$. Furthermore, overlapping phenotypic and immunophenotypic features of smooth muscle and myopericytic cells within single EBVMTs have also been documented, expanding the classification to include hybrid EBV-MTs with features of SMTs and MPCTs [50]. The issues surrounding the classification of EBV-MTs remain contentious but as the understanding and spectrum of these tumors are evolving, splitting of these tumors using the current histopathological diagnostic criteria may be advantageous for future redress.

\section{Distinctive Features}

To date, the histogenesis of myoid cells that may be infected and transformed by EBV include smooth muscle cells and myopericytes. EBV-SMTs have been categorized as leiomyomas, smooth muscle tumors of uncertain malignant potential and leiomyosarcomas based on the diagnostic criteria for HIV-naïve SMTs in various locations [37,38]. Definitive diagnostic criteria for the determination of malignancy in SMTs outside of primary soft tissue, genito-urinary and gastrointestinal tracts are unestablished to date $[6,37,38]$. Pathological features impacting the classification of SMTs include tumor dimensions, cellularity, cytologic atypia, necrosis and hemorrhage, but mitotic activity is the most dependable predictor of malignancy $[6,37,38,60]$. In the urinary bladder, any one of these features or the presence of muscularis propria invasion is adequate to diagnose malignancy. While the presence of any mitotic activity in SMTs of subcutaneous or deep soft tissue is indicative of potential malignancy, the presence of atypia in brain SMTs is a marker of aggressiveness [33]. Diagnostic criteria for gastrointestinal leiomyosarcoma include $\geq 5$ mitoses per 30 high power fields (HPFs) in the absence of spindle cell atypia, $\geq 3$ mitoses per 30HPFs for spindle cell lesions with conspicuous pleomorphism, and $\geq$ 2 mitoses per 30HPFs in epithelioid SMTs [33,37]. Female genital tract leiomyosarcomas are typified by $\geq 10$ mitoses per $10 \mathrm{HPFs}$. However, in the presence of significant hypercellularity, cellular atypia and coagulative necrosis, 5 mitoses per 10HPFs are adequate to diagnose leiomyosarcomas [61].

\section{EBV-SMTs: Demographic and Pathologic Features}

\section{Clinical features}

While EBV-SMTs are associated with low CD4 counts, often $\leq 200$ cells $/ \mu \mathrm{L}$, the relationship with HIV viral load remains undetermined in the English-language literature. More than two thirds of EBV-SMTs are diagnosed within 4 years of HIV infection [6]. The tumor may be the sentinel of HIV/AIDS in the patient or may be associated with chronic HIV infection [48-50]. Furthermore, afflicted patients may be on HAART. There is no gender predilection. The age range of patients with EBV-SMTs is 2.7 to 4 (average: 25) years, but disproportionate AIDS-associated childhood affliction is documented [10,15]. Although EBV-SMTs have been reported in almost every anatomical location and are typified by multifocality as a characteristic clinical finding, the most common documented locations include the central nervous system, spinal cord and column, bronchopulmonary tree, soft tissue of the extremities and gastrointestinal tract $[6,27,34]$. Genito-urinary EBV-SMTs are reported infrequently [28].

\section{Pathology of EBV-SMTs}

Gross features: EBV-SMTs are firm, white, grey, tan, solid and unencapsulated tumors with variable central necrosis, umbilication and infiltration. Depending on the location, some are well-circumscribed nodular or lobulated masses $[15,17]$ while others maybe ill-defined [42]. In hollow organs, EBV-SMTs have a polypoid appearance $[4,9]$. Vertebral tumors may be dumbbell-shaped $[6,15]$.

Microscopic features: EBV-SMTs are characterized by architectural and cellular diversity and, as with SMTs unassociated 
Citation: Khaba MC, Ramdial PK, Pillay B, Steyn AJ, Nargan K (2016) Epstein-Barr Virus-Associated Myoid Tumors in Human Immunodeficiency VirusInfected Patients. J AIDS Clin Res 7: 616. doi:10.4172/2155-6113.1000616

with immunosuppression, are plagued by distinctive criteria for malignancy. Two cell types are described. The first cell type typical of SMTs, is spindle or cigar-shaped with blunted ends and abundant eosinophilic cytoplasm [6,48,50] (Figures $2 \mathrm{~A}$ and $2 \mathrm{~B}$ ). The second cell type is round or oval in shape with a primitive appearance $[6,27,48]$ (Figure 2C). The spindle cells are arranged in short interlacing fascicles (Figure 2A) and the round cells, in a nodular pattern (Figure 2D) [27,50]. Perivascular whorled (Figure 3A) and gaping or hemangiopericytic (Figure 3B) cellular arrangements, demonstrating EBER-positivity (Figure 3C) and a lymphocytic stromal inflammatory infiltrate (Figure 3D), predominantly of T-lymphocytic subtype, are documented $[48,50]$. The cellular EBER-positivity underpins definitive diagnosis. Hypercellularity (Figure 4A), pleomorphism (Figure 4B), necrosis (Figure $4 \mathrm{C}$ ), hemorrhage, variable including negative desmin immunostaining (Figure 4D) and increased proliferation and mitotic indices (Figure 4E) correlate with the malignant behavior of EBVleiomyosarcomas. Estrogen and progesterone hormone receptor studies are negative.

Ultrastructurally, features of smooth muscle histogenesis have been confirmed but nuclear viral particles have not been documented up to now [6].

\section{Histopathological differential diagnosis of EBV-SMTs}

The microscopic differential diagnosis encompasses a wide spectrum of spindle cell lesions that are reflective of the heterogeneity induced by the HIV/AIDS background and the diverse and unusual organs involved, often simultaneously (Table 2). The former specifically includes AIDS-defining infective and neoplastic lesions. Heightened microscopic awareness of EBV-induced SMTs underpins the diagnosis, as it is this suspicion that prompts the performance of EBER testing in these proliferations. Multiple infective histochemical stains, including Ziehl Neelsen and Southgate mucicarmine stains, are pivotal to the diagnosis of mycobacterial and cryptococcal pseudotumors, respectively. While infective inflammatory pseudotumors may demonstrate a partial myofibroblastic response because of a healing response, they are dominated by a CD68 histiocytic immunophenotype $[62,63]$.

Reactive spindle cell lesions, including nodular fasciitis and hypertrophic scar, mimic EBV-SMTs on routine hematoxylin and eosin staining and also share a smooth muscle immunophenotype [60]. However, EBER testing is negative. Similarly fibromatoses

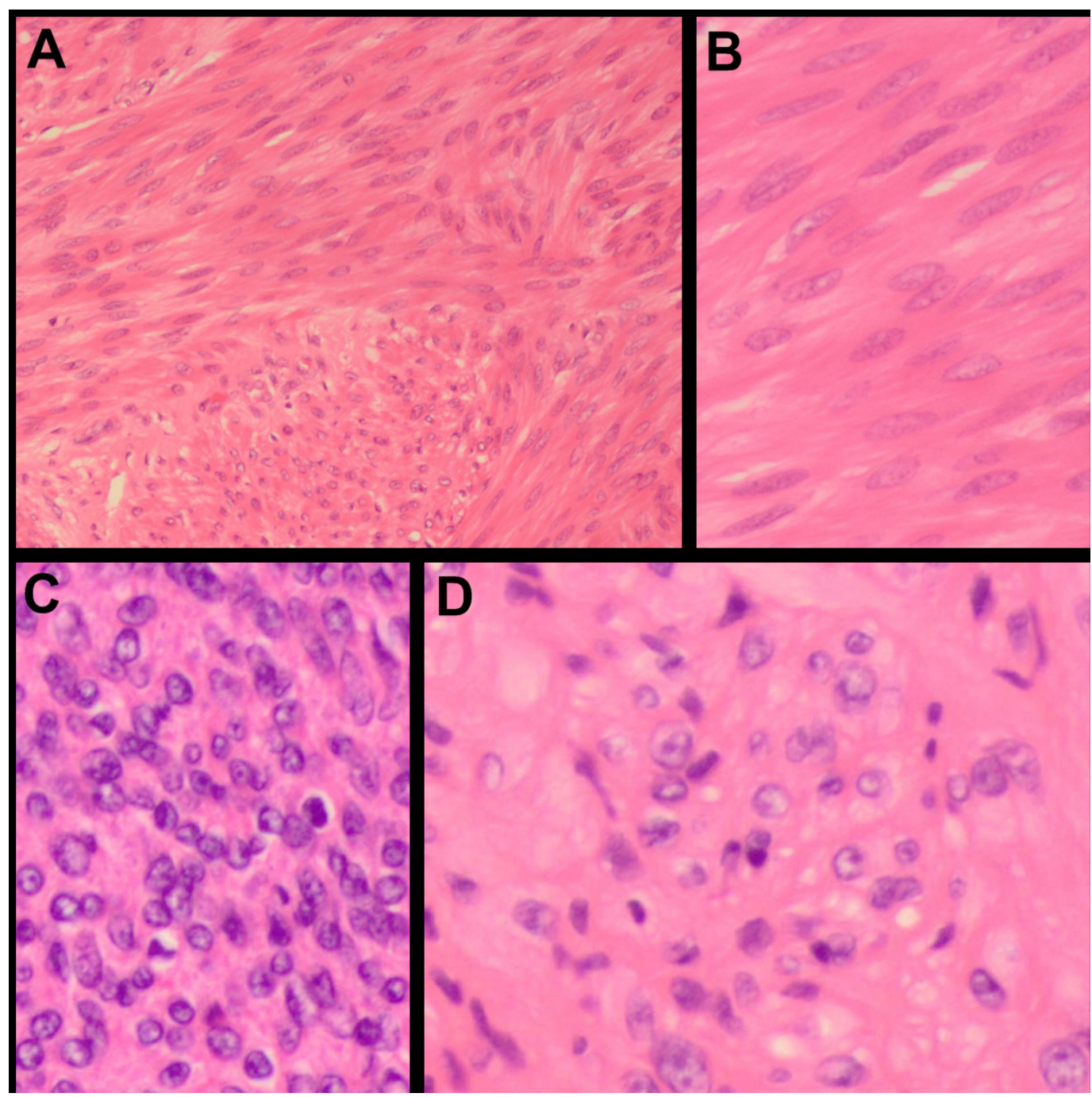

Figure 2: EBV-SMT: Leiomyoma composed of spindle cells arranged in a fascicular pattern (A, hematoxylin and eosin, 120X) and composed of abundant eosinophilic cytoplasm ( $B$, hematoxylin and eosin, 480X). Round cells (C, hematoxylin and eosin, 240X) arranged in nodules (D, hematoxylin and eosin, 240X). 
Citation: Khaba MC, Ramdial PK, Pillay B, Steyn AJ, Nargan K (2016) Epstein-Barr Virus-Associated Myoid Tumors in Human Immunodeficiency VirusInfected Patients. J AIDS Clin Res 7: 616. doi:10.4172/2155-6113.1000616

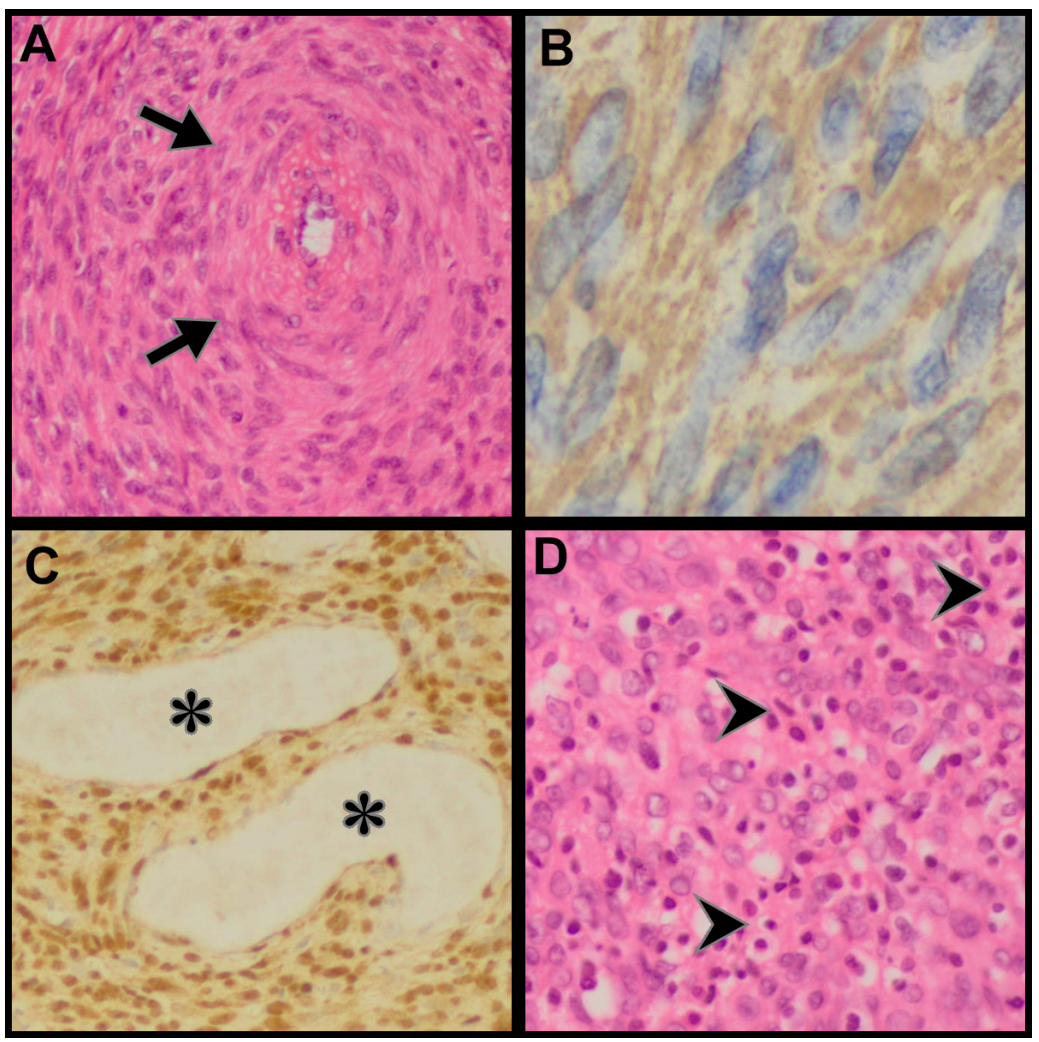

Figure 3: EBV-SMT: Leiomyoma with perivascular (arrows) cellular whorling (A, hematoxylin and eosin 120X), desmin immunopositive cells (B, oil immersion 1200X), EBER-positive cells around gaping blood vessels (asterisks) (C, 120X) and intratumoral lymphocytes (arrowheads) (D, hematoxylin and eosin 120X).

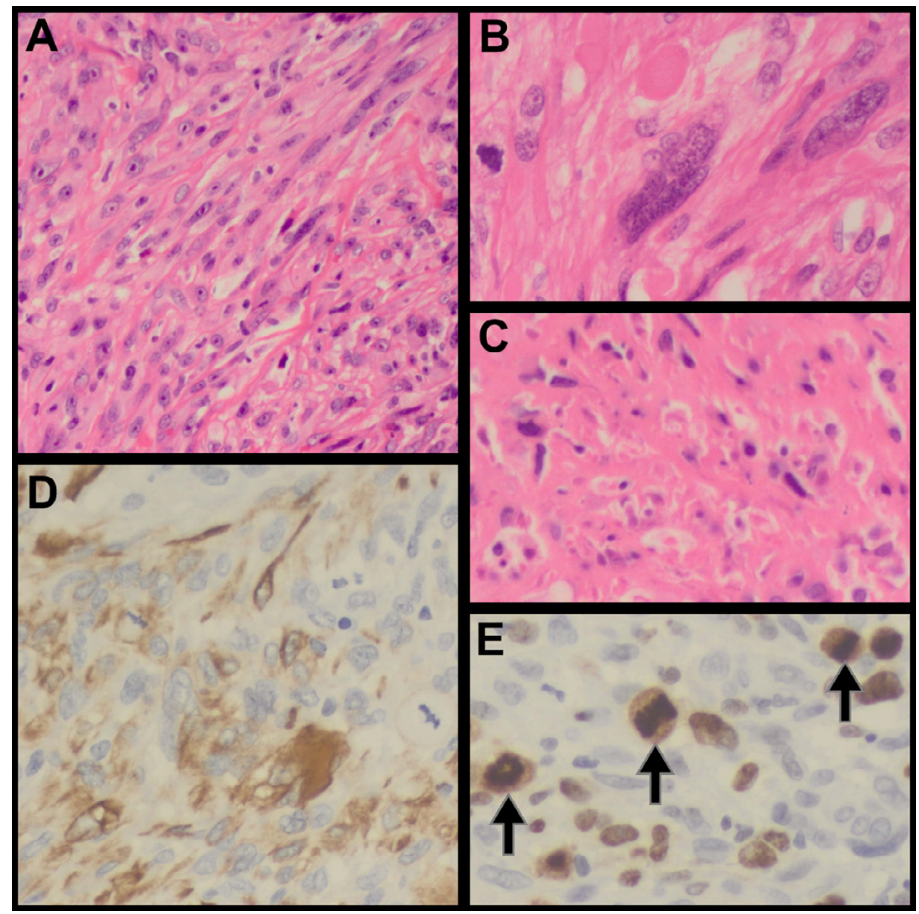

Figure 4: EBV-SMT: Leiomyosarcoma demonstrating a hypercellular, vaguely fascicular growth pattern (A, hematoxylin and eosin 120X), pleomorphism with giant cell transformation (B, hematoxylin and eosin $240 X)$, early necrosis (C, hematoxylin and eosin, 120X), variable desmin immunopositivity (D, 240X), high Ki-67 staining (E, MIB1, oil immersion 1200X) and conspicuous mitoses (arrows). 


A. Non-neoplastic
1. Reactive
- Hypertrophic scar
2. Pseudoneoplastic
- Infective pseudotumor
- Nodular Fasciitis
B. Neoplastic
1. Benign
- Cellular schwannoma
- Cellular fibrous histiocytoma
2. Lewingioma
- Inflammatory myofibroblastic tumor
- Dermatofibrosarcoma protuberans
3. High grade malignancy
- Fibrosarcoma
- Kaposi sarcoma
- Malignant peripheral nerve sheath tumors
- Gastro-intestinal stromal tumor
- Follicular dendritic cell sarcoma

Table 2: Mimickers of EBV-associated smooth muscle tumors.

may demonstrate a variable myoid immunoprofile because of its myofibroblastic lineage $[48,60]$. The neoplastic mimickers include benign and malignant mesenchymal tumors, especially those with a vague or pronounced fascicular pattern. Benign tumors that may mimic EBV-MTs encompass nerve sheath and fibrohistiocytic tumors, including cellular schwannoma and cellular fibrous histiocytoma $[48,50]$. While the former lacks a myoid phenotype and is richly S100 protein immunopositive, cellular fibrous histiocytomas, in contrast, may demonstrate $\alpha$-smooth muscle and muscle-specific actin immunopositivity [64]; however, they are EBER-negative. In addition, the hyperplastic epidermal response, a characteristic feature of cellular fibrous histiocytoma is not described in EBV-SMTs. Dermatofibrosarcoma protuberans, a neoplasm of intermediate malignant potential, is a microscopic pitfall especially in the setting of fibrosarcomatous transformation; CD34 immunopositivity and COL1A1 mutations set it apart from other spindle cell mimickers [48]. Another intermediate tumor, inflammatory myofibroblastic tumor, shares immunophenotypic features with EBV-SMTs, but inflammatory myofibroblastic tumor has a marked inflammatory component, may demonstrate anaplastic lymphoma kinase-1 immunopositivity and is EBER-negative $[48,50,65]$. Of the malignant tumors, Kaposi sarcoma with a solid, spindle cell component may resemble EBV-SMT [48-50]. Viral ancillary testing demonstrates Human herpes virus 8-infected neoplastic cells in Kaposi sarcoma. In contrast to EBV-SMTs, malignant nerve sheath tumors and melanoma are S100 protein-positive and EBER-negative, and extra-intestinal or metastatic gastro-intestinal stromal tumors are CD34 and CD117 positive. Monophasic synovial sarcoma and malignant mesothelioma mimic leiomyosarcoma but epithelial markers, especially epithelial membrane antigen immunopositivity in the former, and mesothelial marker immunopositivity in the latter, facilitate their diagnostic distinction [6,27,48-50]. Dural EBV-SMTs must be distinguished from meningiomas that are epithelial membrane antigen immunopositive $[33,36,48-50]$.

While EBV-SMTs are characterized by common histopathological attributes, irrespective of the cause of immunosuppression, they contain subtle microscopic features that set them apart from conventional, somatic SMTs occurring in HIV-negative and immunocompetent patients. These include the presence of large, round cells with irregular nuclear contours and an immature phenotype, in addition to spindle cells and intratumoral lymphocytes, predominantly of $\mathrm{T}$ subtype
$[6,18,27,34]$. There is a close relationship to the walls of small blood vessels, with proliferation of EBER-positive round and spindle cells within blood vessels and swirling of cells around the vessel $[34,48,60]$. This phenomenon, variably referred to as vascular dysplasia or atypia, has been the basis of speculation that vascular smooth smooth muscle is the site of viral infection in EBV-MTs [48].

\section{EBV-MPCTs: Clinicopathologic Features}

\section{Clinical features}

The clinicopathological spectrum of myopericytoma, first described as a distinct entity in 1998 [66], has evolved to include malignant, hybrid and intravascular forms $[47,49,50,67]$. In addition, an association between EBV and immunosuppression was reported for the first time a decade later [59]. The association with AIDS-associated immunodeficiency is evidenced by prior opportunistic infections and low peripheralblood CD 4 cell counts, ranging from $20-63 / \mathrm{mL}$, in afflicted patients $[46,49,50]$. EBV-MPCT, however, remains a rarely reported tumor, even from countries ravaged by AIDS. MPCT is classified as a member of the group of perivascular tumors that also includes glomus tumors, haemangiopericytomas, glomangiopericytoma and adult myofibromatosis [66]. MPCTs in HIV-naïve patients are identified mainly in subcutaneous and superficial soft tissues of the extremities in middle adulthood [66-70]. They usually present as solitary, painless and slow-growing masses. Occurrence outside the somatic soft tissues, including the brain, thoracic cavity, lip and nasal cavity, is documented rarely $[66,67]$. In contrast MPCTs in AIDS patients commonly occur outside somatic soft tissue, including the bronchus, tongue, vocal cord, brain, hepatobiliary system and spinal epidural tissue; these sites are only rarely involved in HIV-naïve patients [46]. Furthermore, the solitary presentation of sporadic MPCT differs from the multifocality reported in the AIDS context $[46,50,59]$. The association with EBV in the HIV/AIDS setting is unique as it is conspicuously absent in sporadic MPCTs studied as control cases [46]. While EBV-MPCTs are reported uncommonly in the global literature, visceral biliary and intracranial tumors have been documented $[46,49,50,59]$. Similar to EBV-MPCTs in HIV-naïve patients, benign and malignant variants are described $[49,50]$.

\section{Pathological features}

Gross features: EBV-MPCTs are generally unencapsulated, greywhite tumors of firm consistency $[45,46]$ with a nodular or polypoid gross appearance (Figure 5A).

Microscopic features: EBV-MPCTs are composed of sheets of round, oval and spindle-shaped neoplastic cells (Figure 5B). The latter have eosinophilic cytoplasm and may merge into fascicles, highly reminiscent of smooth muscle cells $[46,50,59]$. The nucleoli are frequently vesicular with variable nucleolar prominence and hyperchromasia. The cellular sheets are punctuated by slit-like, staghorn and dilated vascular channels [46,49,50,59] (Figure 5C). In addition, MPCTs display a prominent concentric and multilayered perivascular proliferation of spindle cells $[46,49,50]$ that are EBER-positive (Figure 5D). The variable inflammatory background, composed of $\mathrm{CD} 4+$ and $\mathrm{CD} 8+$ lymphocytes and CD68-positive macrophages, may be a marker of an immune reconstitution reaction $[49,50]$. The lesional cells are $\mathrm{H}$-caldesmon (Figure 6A), a-smooth muscle actin (Figure 6B) and muscle specific actin immunopositive and desmin immunonegative (Figure 6C) [35,45,62]. Even where cells display a spindled appearance with eosinophilic cytoplasm and a fascicular arrangement, similar to smooth muscle, they retain a desmin 
Citation: Khaba MC, Ramdial PK, Pillay B, Steyn AJ, Nargan K (2016) Epstein-Barr Virus-Associated Myoid Tumors in Human Immunodeficiency VirusInfected Patients. J AIDS Clin Res 7: 616. doi:10.4172/2155-6113.1000616

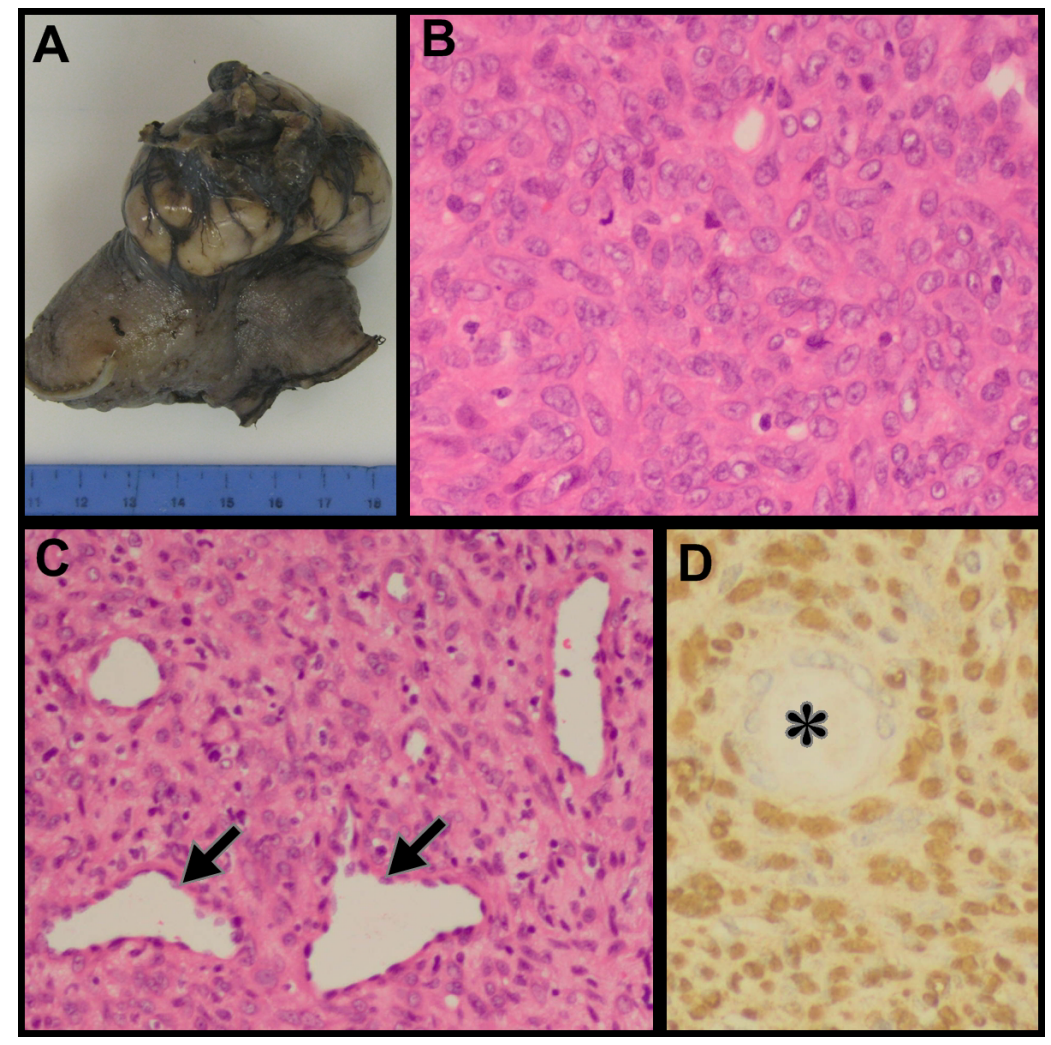

Figure 5: EBV-MPCT: Benign polypoid intestinal MPCT (A) composed of round, oval and spindle cells (B, hematoxylin and eosin 120X), dilated and staghorn-shaped (arrows) vessels (C, hematoxylin and eosin 120X) and EBER-positive cellular mass spinning off blood vessel (asterisk) wall $(D, 120 X)$.

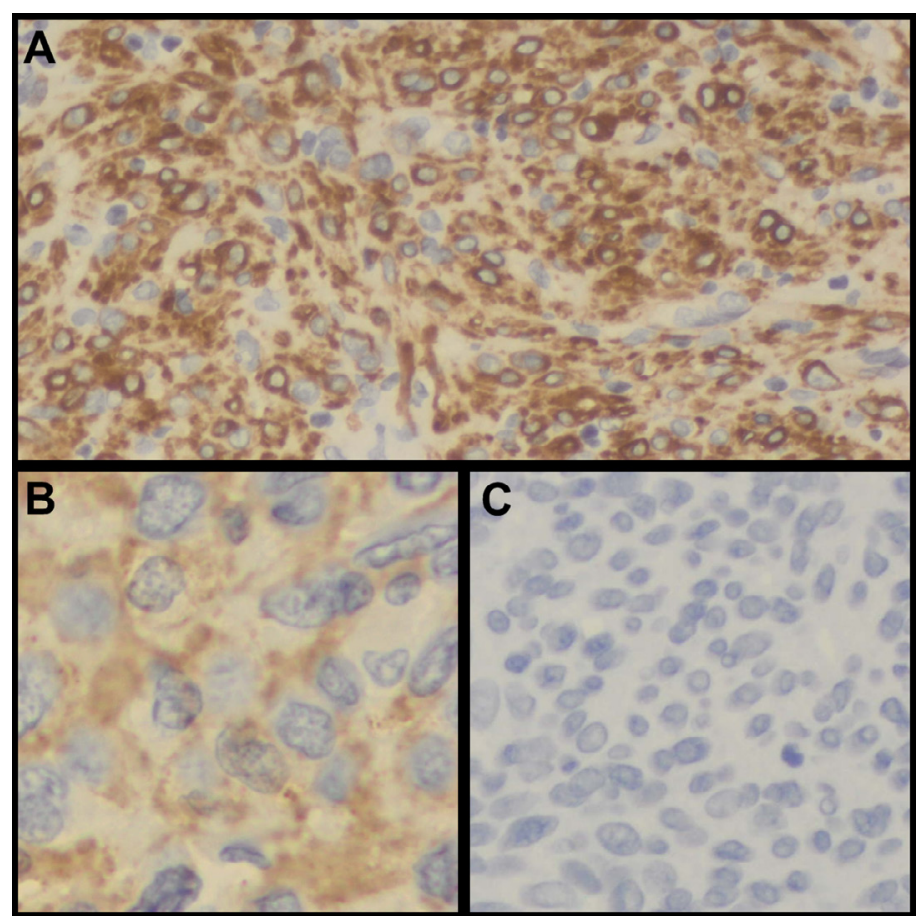

Figure 6: EBV-MPCT: Benign MPCT displaying H-caldesmon (A, 480X) and $\alpha$-smooth muscle actin immunopositivity (B, oil immersion 1200X) and desmin immunonegativity (C, 120X) 
immunonegative myopericytic immunophenotype [45,46,49,50]. Malignant EBV-MPCTs are hypercellular tumors (Figure 7A) with cytomorphological pleomorphism (Figure 7B), foci of necrosis (Figure 7C), retained EBER-immunopositivity (Figure 7D) and increased proliferative (Figure 7E) and mitotic indices $[49,50,66]$.

\section{Histopathological differential diagnosis of EBV-MPCTs}

EBV in-situ hybridization is the most powerful diagnostic tool in the histopathologist's armamentarium for the diagnosis of EBV-MTs. Similar to EBV-SMTs, the differential diagnosis of EBV-MPCTs is influenced by the anatomic location of the tumor. The first mimicker, common to all locations in the AIDS setting, is EBV-SMT $[45,46,49,50]$. The global literature documents shared phenotypic overlap by way of round, oval and spindle cells. However, myopericyte-derived tumors are consistently desmin immunonegative. Further attention must be directed to hybrid EBV-MTs in which EBER-rich round and spindle cells co-exist but the latter are desmin immunonegative and former, desmin immunopositive [50]. As myopericytes spin off vessel walls in a concentric manner, residual vascular mural smooth muscle cells may resemble a neoplastic smooth muscle component, but the latter are desmin immunopositive and EBER-negative.

Kaposi sarcoma that also occurs in somatic soft tissue, skin and visceral sites is another HIV/AIDS-associated mimicker [50]. While both tumors are richly vascularized and contain a lymphoplasmacytic infiltrate, the vasculature in Kaposi sarcoma is slit-like and congested. EBV-MPCTs contain dilated, often empty, blood vessels with a staghorn configuration. Kaposi sarcoma also demonstrates erythrocyte extravasation and eosinophilic hyaline globules [49,50]. Nerve sheath tumors in any location are distinguished from EBV-MPCT by S100 immunopositivity. The presence of an inflammatory component and round, oval and spindle cells is shared with inflammatory myofibroblastic tumor (IMFT), but the inflammatory component is more dense and heterogeneous in IMFT $[46,50]$. In contrast to EBV-MPCT, 60\% of IMFTs express anaplastic lymphoma kinase-1 protein. Glomus tumors share closest morphological similarity with EBV-MPCT, as both tumors are typified by round, uniform cells with well-demarcated nuclei and cellular, concentric layering around vessel walls. However, slight separation of the spindle cells from the vessel wall is seen in glomus tumor that contrasts with the direct spinning off of cells from the vessel wall in MPCT [50,66].

In intracranial locations, solitary fibrous tumor/ haemangiopericytoma requires distinction from MPCT as both share cytomorphological and vascular architectural similarities. Although the former shares an actin immunopositive, desmin immunonegative profile with EBV-MPCT, it differs from EBV-MPCT by its diagnostic CD34 immunopositivity [59]. In the gastrointestinal tract, gastrointestinal stromal tumor is distinguished from EBV-MPCT by CD117, CD34 and H-caldesmon immunonegativity [46]. In the AIDS context, infective mycobacterial and fungal pseudotumors with round, oval and spindled CD68-immunopositive histiocytes and organizing inflammatory myofibroblastic responses must be distinguished from EBV-MPCT that shares an actin-rich myofibroblastic but not a CD68positive histiocytic immunophenotype. A high index of suspicion for infective pseudotumors in the context of HIV/AIDS underpins the conduction of infective special stains and the identification of infective agents therein [63].

\section{Outcome of EBV-MTs}

Despite the diagnostic challenges and varied criteria for the diagnostic confirmation of benign and malignant EBV-MTs in different locations, the outcomes of the tumors are dependent on the immune status of the patient, co-morbid infective diseases and the atypical locations of the tumors $[27,34]$. These factors have underpinned the controversies surrounding outcome in EBV-SMTs. While mortality figures approximating $26 \%$ are reported in EBV-MTs, death due directly to EBV-MTs has been documented in approximately $6 \%$ of patients [45]. There is a four times possibility that death in patients with EBV-SMTs is more likely to be caused by another co-morbid condition [6]. It is not possible to confirm whether multiple tumors are part of the multifocal evolutionary pathogenesis or whether they are metastases in the absence of clonal studies [51]. EBV-SMTs are resistant to cytotoxic chemotherapy that may also be tolerated suboptimally by immunocompromized patients [36]. The impact of HAART on EBV-SMTs is poorly reported, but size stabilization and regression with modest increase in CD4 counts are documented [6]. Prolonged depressed CD4 cell counts accompanied by persistently high viral loads may accelerate tumor growth and recurrence risks [36].

The current management recommendation for EBV-MTs is treatment on an individual basis with complete surgical excision and follow-up as the treatment strategy of choice. However, in sites where tumors are not completely amenable to surgical extirpation, such as the craniospinal column, head and neck sites and pancreaticobiliary ductal system, site-related complications impact outcome. EBV-specific immunotherapy including mTOR inhibitors and demethylating agents are emerging potential therapeutic options for EBV-SMTs [57,71]. When complete surgical excision is not feasible, chemotherapy, although with limited options, and radiotherapy may effectively shrink EBV-MTs, facilitate resection, improve survival and decrease recurrences. Combination chemotherapy or single chemotherapeutic agents may be employed. Ifosfamide and doxorubicin or gemcitabine and docetaxel are described as combination chemotherapy or gemcitabine and doxorubicin have been used as single agents [36] Challenges on the treatment coalface include co-morbid infectionassociated neutropenia, outpatient management, patient compliance and uncertainty of chemotherapeutic efficacy because of the sparse global literature on the topic $[36,57,71]$. Whether HAART impedes the growth and spread of malignant EBV-MTs remains uninvestigated.

\section{Uncertainties, Literature Gaps, Future Directions}

Despite the expanding spectrum and evolving understanding of EBV-MTs, the dearth of reports on the management and outcomes of EBV-MTs impact comprehensive understanding of these tumors. Gaps and uncertainties with respect to standardized diagnostic approaches, understanding and treatment exist (Table 3); attempts to narrow these shortcomings are summarized below:

\section{Global Reporting on EBV-MT}

EBV-MTs are a well-recognized HIV/AIDS immunosuppressionrelated tumor but the entity is reported rarely, especially from countries devastated by AIDS. It is possible that healthcare teams from these AIDS-epidemic areas are understaffed and overworked and the lack of reports may therefore represent a function of non-reporting rather than tumor rarity. Attempts to facilitate investigation of EBVMTs from all AIDS-afflicted countries by willing global partners may be the solution to improve understanding, definition, classification and treatment strategies thereof.

\section{Histogenesis and Pathogenesis}

Immunosuppression and EBV-infection are important cofactors in the etiopathogenesis of EBV-MTs. Not only the exact 
Citation: Khaba MC, Ramdial PK, Pillay B, Steyn AJ, Nargan K (2016) Epstein-Barr Virus-Associated Myoid Tumors in Human Immunodeficiency VirusInfected Patients. J AIDS Clin Res 7: 616. doi:10.4172/2155-6113.1000616

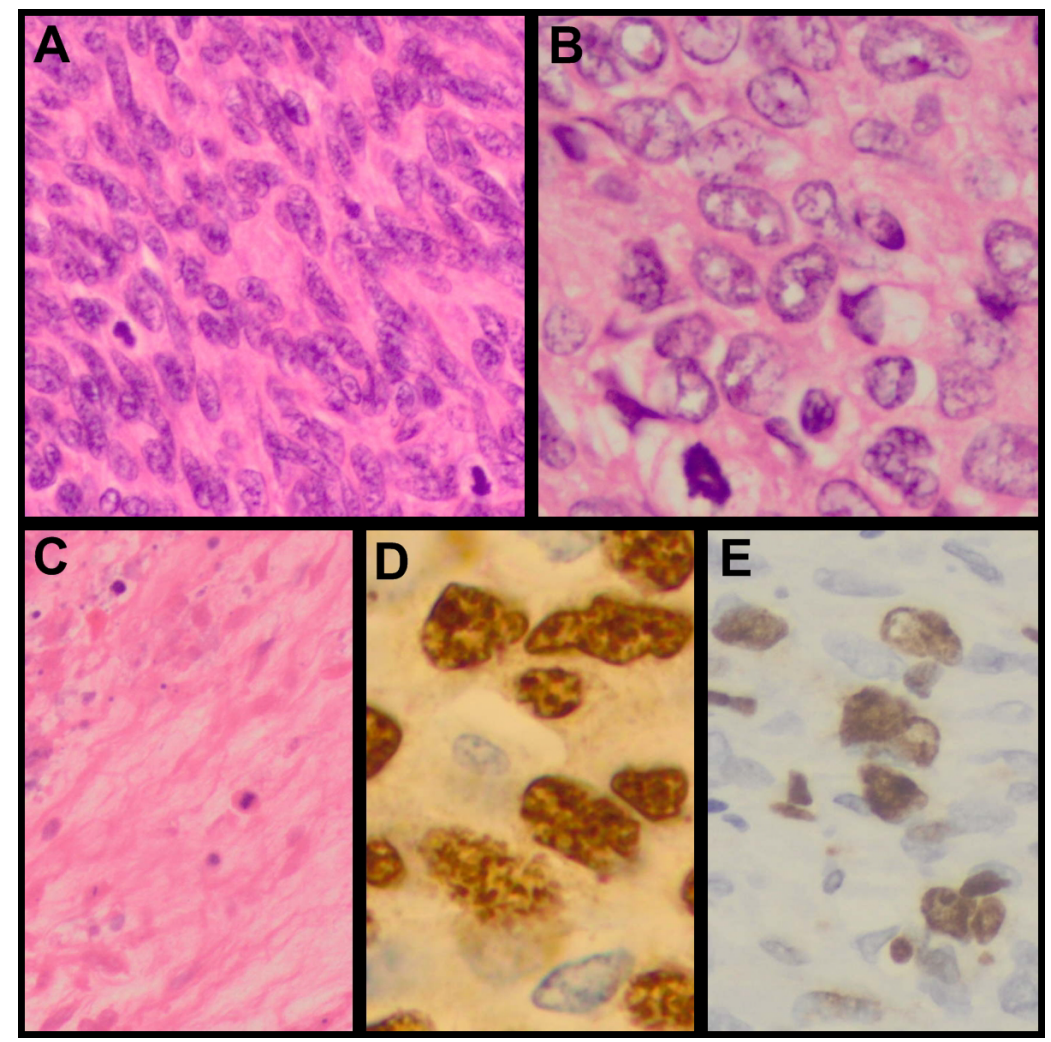

Figure 7: EBV-MPCT: Malignant MPCT typified by hypercellularity (A, hematoxylin and eosin 120X), pleomorphism (B, hematoxylin and eosin 480X), necrosis, (C, hematoxylin and eosin 120X), EBER-positivity (D, 240X) and high Ki67 immunostaining (E, MIB1, oil immersion 1200X).

\begin{tabular}{|c|c|}
\hline Issue & Potential Future Directions \\
\hline 1. EBV-MT rarity versus under-reporting & $\begin{array}{l}\text { Global assistance to countries: } \\
\text { - unable to diagnose for technical reasons } \\
\text { - unable to report: time constraints } \\
\text { - } \text { unable to report: staffing limitations } \\
\text { electronic challenges }\end{array}$ \\
\hline $\begin{array}{l}\text { 2. Diagnostic/ pathogenetic challenges: poor laboratory infrastructure/ testing } \\
\text { platforms }\end{array}$ & $\begin{array}{l}\text { Referral to partnered laboratories } \\
\text { - Poor immunohistochemical and in-situ platforms } \\
\text { - Morphological consultation } \\
\text { - } \text { CD4 and viral loads } \\
\text { Role of immune reconstitution }\end{array}$ \\
\hline 3. Histogenesis & $\begin{array}{l}\text { Adequate description and immunophenotyping to determine origin from: } \\
\text { - } \quad \text { primitive mesenchymal cell } \\
\text { - } \text { myopericyte } \\
\text { vascular mural smooth muscle }\end{array}$ \\
\hline 4. Classification of EBV-MTs & \begin{tabular}{|l} 
Attention to: \\
- $\quad$ Distinctive diagnostic criteria \\
- $\quad$ Defined immunophenotyping \\
- \\
Recognition of hybrid tumors
\end{tabular} \\
\hline 5. Predictors of malignancy & $\begin{array}{l}\text { Careful reporting of: } \\
\begin{array}{c}\text { - Site dependent diagnostic criteria for EBV-MTs } \\
\text { - }\end{array} \text { Clonal assessment to determine multifocality versus metastases }\end{array}$ \\
\hline 6. Treatment & $\begin{aligned} \text { Roles for: } \\
\text { - HAART } \\
\text { - EBV-antiretroviral therapy } \\
\text { - } \quad \text { Chemoradiation } \\
\text { Biological agents }\end{aligned}$ \\
\hline
\end{tabular}

EBV: Epstein Barr Virus; EBV-MT: Epstein Barr Virus-Associated Myoid Tumor; HAART: Highly Active Anti-Retroviral Therapy Table 3: Uncertainties, literature gaps and potential future directions.

origin of EBV-MT, viz. from differentiated vascular smooth muscle, perivascular myocyte or primitive mesenchymal undifferentiated cells, but the exact mode of entry of EBV into myoid cells and their transformation are also unexplained. Ab initio entry into myoid cells must be investigated and distinguished from the alternate possibility of infection of transformed myoid cells [50]. 
Citation: Khaba MC, Ramdial PK, Pillay B, Steyn AJ, Nargan K (2016) Epstein-Barr Virus-Associated Myoid Tumors in Human Immunodeficiency VirusInfected Patients. J AIDS Clin Res 7: 616. doi:10.4172/2155-6113.1000616

\section{EBV-MT Classification}

The broad spectrum of EBV-MTs includes EBV-SMTs, EBVMPCTs and hybrid EBV-MTs [50]. While the distinguishing features have included a spindle cell component with eosinophilic cytoplasm, the presence of a round cell component, or an admixture of these cell types, and the importance of desmin immunostaining in the distinction of EBV-MPCT from EBV-SMT cannot be overvalued. Desmin immunoprofiles are inconsistently reported in EBV-SMTs. Co-identification of vascular myoid and myopericytic cells have also led to the recognition of hybrid EBV-MTs. It is therefore recommended that future reports be standardized to include detailed phenotypic and immunophenotypic profiles of EBV-MTs [44].

\section{Predictors of Malignancy and Outcome}

The diagnostic criteria and predictors of outcome of EBV-MTs remain controversial. The mortality related to EBV-MTs in AIDS patients is a function of their complete resectability and control of comorbid AIDS-associated opportunistic infections. Mortality of patients with EBV-MTs approximate $26 \%$ but death due specifically to direct tumor effects has been reported in $6 \%$ of patients $[6,46,50]$. The longterm survival that has been reported in patients with multifocal tumors strengthens the viewpoint that multiple EBV-MTs are multifocal rather than metastatic tumors [4,59]. The non-surgical therapeutic options are limited. The exact roles of HAART in tumor regression and flares, as a manifestation of immune reconstitution, require investigation $[6,50]$. Chemotherapy, radiation, combined chemoradiation and personalized biological therapy are emerging management options [36,57,71].

\section{Conclusion}

While the recognition of myoid tumors in the background of immunosuppression represented a crucial pathogenetic landmark, this was heightened by the discovery of the EBV and HIV associations. Although uncertainties in respect of etiopathogenetic pathways, validated diagnostic and prognostic criteria, outcome and therapy prevail, viral associations justify expanded antiviral therapy as therapeutic options. The recognition of malignant EBV-MTs justify the use of chemoradiation, as for SMTs in HIV-naïve settings, but such measures must be undertaken with insight into patients' immune status. In an attempt to improve global understanding and perspectives of EBV-MTs in the HIV/AIDS context, healthcare researchers, especially those in developing countries most afflicted by the AIDS pandemic, must be encouraged to report on their experiences and challenges related to the recognition, diagnosis, treatment and outcomes thereof.

\section{References}

1. Gingues S, Gill MJ (2006) The impact of highly active antiretroviral therapy on the incidence and outcomes of AIDS-defining cancers in Southern Alberta. HIV Med 7: 369-377.

2. Mitsuyasu RT (2014) Non-AIDS-defining cancers. Top Antivir Med 22: 660-665.

3. Dominelli GS, Jen R, Park K, Shaipanich T (2014) Tracheal Epstein-Barr virusassociated smooth muscle tumour in an HIV-positive patient. Can Respir J 21 : 334-336.

4. Chadwick EG, Connor EJ, Hanson IC, Joshi VV, Abu-Farsakh H, et al. (1990) Tumors of smooth-muscle origin in HIV-infected children. JAMA 263: $3182-$ 3184.

5. Hussein K, Rath B, Ludewig B, Kreipe H, Jonigk D (2014) Clinico-pathological characteristics of different types of immunodeficiency-associated smooth muscle tumours. Eur J Cancer 50: 2417-2424.
6. Purgina B, Rao UN, Miettinen M, Pantanowitz L (2011) AIDS-related EBV associated smooth muscle tumors: A review of 64 published cases. Patholog Res Int 2011: 561548.

7. van Hoeven KH, Factor SM, Kress Y, Woodruff JM (1993) Visceral myogenic tumors. A manifestation of HIV infection in children. Am J Surg Pathol 17: 11761181.

8. Ninane J, Moulin D, Latinne D, De Bruyere M, Scheiff JM, et al. (1985) AIDS in two African children--one with fibrosarcoma of the liver. Eur J Pediatr 144 385-390.

9. Radin DR, Kiyabu M (1992) Multiple smooth-muscle tumors of the colon and adrenal gland in an adult with AIDS. AJR Am J Roentgenol 159: 545-546.

10. Balarezo FS, Fabiola S, Joshi VV (2002) Proliferative and neoplastic disorders in children with acquired immunodeficiency syndrome. Adv Anat Pathol 9: 360-370.

11. Balsam D, Segal S (1992) Two smooth muscle tumors in the airway of an HIVinfected child. Pediatr Radiol 22: 552-553.

12. Bargiela A, Rey JL, Díaz JL, Martínez A (1999) Meningeal leiomyoma in an adult with AIDS: CT and MRI with pathological correlation. Neuroradiology 41 : 696-698.

13. Brown HG, Burger PC, Olivi A, Sills AK, Barditch-Crovo PA, et al. (1999) Intracranial leiomyosarcoma in a patient with AIDS. Neuroradiology 41: 35-39.

14. Bluhm JM, Yi ES, Diaz G, Colby TV, Colt HG (1997) Multicentric endobronchia smooth muscle tumors associated with the Epstein-Barr virus in an adult patient with the acquired immunodeficiency syndrome: A case report. Cancer 80: 1910-1913.

15. Choi S, Levy ML, Krieger MD, McComb JG (1997) Spinal extradural leiomyoma in a pediatric patient with acquired immunodeficiency syndrome: Case report Neurosurgery 40: 1080-1082.

16. de Chadarévian JP, Wolk JH, Inniss S, Lischner HW, d'Amore F, et al. (1997) A newly recognized cause of wheezing: AIDS-related bronchial leiomyomas. Pediatr Pulmonol 24: 106-110.

17. Jimenez-Heffernan JA, Hardisson D, Palacios J, Garcia VM, Gamallo C, et a (1995) Adrenal gland leiomyoma in a child with acquired immunodeficiency syndrome. Pediatr Pathol Lab Med 15: 923-929.

18. McClain KL, Leach CT, Jenson HB, Joshi VV, Pollock BH, et al. (1995) Association of Epstein-Barr virus with leiomyosarcomas in children with AIDS N Engl J Med 332: 12-18.

19. McLoughlin LC, Nord KS, Joshi VV, DiCarlo FJ, Kane MJ (1991) Disseminated leiomyosarcoma in a child with acquired immune deficiency syndrome. Cancer 67: 2618-2621.

20. Molle ZL, Bornemann P, Desai N, Clarin E, Anderson V, et al. (1999) Endoscopic features of intestinal smooth muscle tumor in a child with AIDS Dig Dis Sci 44: 910-915.

21. Orlow SJ, Kamino H, Lawrence RL (1992) Multiple subcutaneous leiomyosarcomas in an adolescent with AIDS. Am J Pediatr Hematol Oncol 14: $265-268$

22. Ross JS, Rosario AD, Bui HX, Sonbati H, Solis O (1992) Primary hepatic leiomyosarcoma in a child with the acquired immunodeficiency syndrome. Human Pathol 23: 69-72.

23. Steel TR, Pell MF, Turner JJ, Lim GH (1993) Spinal epidural leiomyoma occurring in an HIV-infected man. Case report. J Neurosurg 79: 442-445.

24. Tomà $P$, Loy $A$, Pastorino $C$, Derchi LE (1997) Leiomyomas of the gallbladder and splenic calcifications in an HIV-infected child. Pediatr Radiol 27: 92-94.

25. Barbashina V, Heller DS, Hameed M, Albanese E, Goldstein M, et al. (2000) Splenic smooth-muscle tumors in children with acquired immunodeficiency syndrome: Report of two cases of this unusual location with evidence of an association with Epstein-Barr virus. Virchows Arch 436: 138-139.

26. Cheuk W, Li PCK, Chan JKC (2002) Epstein-Barr virus-associated smooth muscle tumour: A distinctive mesenchymal tumour of immunocompromised individual. Pathology 34: 245-249.

27. Deyrup AT (2008) Epstein-Barr virus-associated epithelial and mesenchymal neoplasms. Hum Pathol 39: 473-483.

28. Khunamornpong S, Sukpan K, Suprasert P, et al (2007) Epstein-Barr virusassociated smooth muscle tumor presenting as a vulvar mass in an acquired immunodeficiency syndrome patient: A case report. Int J Gynecol Cancer 17 1333-1339. 
Citation: Khaba MC, Ramdial PK, Pillay B, Steyn AJ, Nargan K (2016) Epstein-Barr Virus-Associated Myoid Tumors in Human Immunodeficiency VirusInfected Patients. J AIDS Clin Res 7: 616. doi:10.4172/2155-6113.1000616

29. Liebowitz D (1995) Epstein-Barr virus--an old dog with new tricks. N Engl J Med 332: 55-57

30. Suankratay C, Shuangshoti S, Mutirangura A, Prasanthai V, Lerdlum S, et al. (2005) Epstein-Barr virus infection-associated smooth-muscle tumors in patients with AIDS. Clin Infect Dis 40: 1521-1528.

31. Thong JF, Chuah KL (2009) EBV-associated smooth muscle tumour presenting as a parapharyngeal mass--a rare presentation. Auris Nasus Larynx 36: 120122.

32. Wong KH, Chan KC, Lee SS, Lai ST, Lee N, et al. (2007) Epstein-Barr virusassociated smooth muscle tumor in patients with acquired immunodeficiency syndrome. J Microbiol Immunol Infect 40: 173-177.

33. Zevallos-Giampietri EA, Yañes HH, Puelles JO, Barrionuevo C (2004) Primary meningeal Epstein-Barr virus-related leiomyosarcoma in a man infected with human immunodeficiency virus: Review of literature, emphasizing the differential diagnosis and pathogenesis. Appl Immunohistochem Mol Morpho 12: 387-391.

34. Deyrup AT, Lee VK, Hill CE, Cheuk W, Toh HC, et al (2006) Epstein-Barr virus-associated smooth muscle tumors are distinctive mesenchymal tumors reflecting multiple infection events: A clinicopathologic and molecular analysis of 29 tumors from 19 patients. Am J Surg Pathol 30: 75-82.

35. Guillou L, Coindre JM, Bonichon F, Nguyen BB, Terrier P, et al. (1997) Comparative study of the National Cancer Institute and the French Federation of Cancer Centers Sarcoma Group grading systems in a population of 410 adult patients with soft tissue sarcoma. J Clin Oncol 15: 350-362.

36. Gupta S, Havens PL, Southern JF, Firat SY, Jogal SS (2010) Epstein-Bar virus-associated intracranial leiomyosarcoma in an HIV-positive adolescent. J Pediatr Hematol/Oncol 32: e144-e147.

37. Miettinen M, Fetsch JF (2006) Evaluation of biological potential of smooth muscle tumours. Histopathology 48: 97-105.

38. Moore Dalal K, Antonescu CR, DeMatteo RP, Maki RG (2008) EBVassociated smooth muscle neoplasms: Solid tumors arising in the presence of immunosuppression and autoimmune diseases. Sarcoma.

39. Pantanowitz L, Schlecht HP, Dezube BJ (2006) The growing problem of nonAIDS-defining malignancies in HIV. Curr Opin Oncol 18: 469-478.

40. Chang JYF, Wang CS, Hung CC, Tsai TF, Hsiao CH (2002) Multiple EpsteinBarr virus-associated subcutaneous angioleiomyomas in a patient with acquired immunodeficiency syndrome. Br J Dermatol 147: 563-567.

41. Kim JW, Lee DK, Fishman M (2010) Orbital smooth muscle tumor associated with Epstein-Barr virus in a human immunodeficiency virus-positive patient. Arch Opthalmol 128: 1084-1085.

42. Jenson HB, Leach CT, McClain KL, Joshi VV, Pollock BH, et al. (1997) Benign and malignant smooth muscle tumors containing Epstein-Barr virus in children with AIDS. Leuk Lymphoma 27: 303-314.

43. Jenson HB, Montalvo EA, McClain KL, Ench Y, Heard P, et al. (1999) Characterization of natural Epstein-Barr virus infection and replication in smooth muscle cells from a leiomyosarcoma. J Med Virol 57: 36-46.

44. Prévot S, Néris J, de Saint Maur PP (1994) Detection of Epstein-Barr virus in an hepatic leiomyomatous neoplasm in an adult human immunodeficiency virus 1-infected patient. Virchows Archiv 425: 321-325.

45. Gallien S, Zuber B, Polivka M, Lagrange-Xelot M, Thiebault JB, et al. (2008) Multifocal Epstein-Barr virus-associated smooth muscle tumor in adults with AIDS: Case report and review of the literature. Oncology 74: 167-176.

46. Lau PP, Wong OK, Lui PC, Cheung OY, Ho LC, et al. (2009) Myopericytoma in patients with AIDS: A new class of Epstein-Barr virus-associated tumor. Am J Surg Pathol 33: 1666-1672.

47. McMenamin ME, Fletcher CDM (2002) Malignant myopericytoma: Expanding the spectrum of tumours with myopericytic differentiation. Histopathology 41: 450-460.

48. Ramdial PK, Sing Y, Deonarain J, Hadley GP, Singh B (2011) Dermal EpsteinBarr virus-associated leiomyosarcoma: Tocsin of acquired immunodeficiency syndrome in two children. Am J Dermatopathol 33: 392-396.

49. Ramdial PK, Sing Y, Deonarain J, Singh B, Allopi L, et al. (2011) Periampullary Epstein-Barr virus-associated myopericytoma. Hum Pathol 42: 1348-1354.
50. Ramdial PK, Sing Y, Deonarain J, Vaubell Jl, Naicker S, et al. (2011) Extrauterine myoid tumours in patients with acquired immunodeficiency syndrome A clinicopathological re-appraisal. Histopathology 59: 1122-1134.

51. Delecluse HJ, Feederle R, O'Sullivan B, Taniere P (2007) Epstein Barr virusassociated tumours: An update for the attention of the working pathologist. $J$ Clin Pathol 60: 1358-1364.

52. Proceedings of the IARC Working Group on the Evaluation of Carcinogenic Risks to Humans. Epstein-Barr virus and Kaposi's sarcoma herpes virus/ human herpes virus 8. Lyon, France, 17-24 June 1997 (1997) IARC Monogr Eval Carcinog Risks Hum 70: 1-492.

53. Thompson MP, Kurzrock R (2004) Epstein-Barr virus and cancer. Clin Cancer Res 10: 803-821.

54. Lee ES, Locker J, Nalesnik M, Reyes J, Jaffe R, et al. (1995) The association of Epstein-Barr virus with smooth-muscle tumors occurring after organ transplantation. N Engl J Med 332: 19-25

55. Shen Q, Feng W, Long MS, Duan X, Jaijakul S, et al. (2011) Multicentric hepatic EBV-associated smooth muscle tumors in an AIDS patient: A case report, investigation of $\mathrm{mTOR}$ activation and review of the literature. Int $\mathrm{J}$ Clin Exp Pathol 4: 421-429

56. Bayliss GJ, Wolf H (1980) Epstein--Barr virus-induced cell fusion. Nature 287 164-165.

57. Ong KW, Teo M, Lee V, Ong D, Lee A, et al. (2009) Expression of EBV latent antigens, mammalian target of rapamycin, and tumor suppression genes in EBV-positive smooth muscle tumors: Clinical and therapeutic implications. Clin Cancer Res 15: 5350-5358.

58. Hill MA, Araya JC, Eckert MW, et al (1997) Tumor specific Epstein-Barr virus infection is not associated with leiomyosarcoma in human immunodeficiency virus negative individuals. Cancer 80: 204-210.

59. Calderaro J, Polivka M, Gallien S, Bertheau P, Thiebault JB, et al. (2008) Multifocal Epstein-Barr virus (EBV)-associated myopericytoma in a patient with AIDS. Neuropathol Appl Neurobiol 34: 115-117.

60. Weiss SW (2002) Smooth muscle tumors of soft tissue. Adv Anat Pathol 9 351-359.

61. Keller NA, Godoy H (2015) Leiomyosarcoma of the vagina: An exceedingly rare diagnosis. Case Rep Obstet Gynecol 2015: 363895.

62. Tan GC, Yap YP, Shiran MS, Sabariah AR, Pathmanathan R (2009) Cutaneous mycobacterial spindle cell pseudotumour. BMJ Case Rep 2009.

63. Sing Y, Ramdial PK (2007) Cryptococcal inflammatory pseudotumors. Am J Surg Pathol 31: 1521-1527.

64. Luzar B, Calonje E (2010) Cutaneous fibrohistiocytic tumours - an update. Histopathology 56: 148-165.

65. Gleason BC, Hornick JL (2008) Inflammatory myofibroblastic tumours: Where are we now? J Clin Pathol 61: 428-437.

66. Granter SR, Badizadegan K, Fletcher CD (1998) Myofibromatosis in adults, glomangiopericytoma and myopericytoma: A spectrum of tumors showing perivascular myoid differentiation. Am J Surg Pathol 22: 513-525.

67. McMenamin ME, Calonje E (2002) Intravascular myopericytoma. J Cutan Pathol 29: 557-561.

68. Cao JH, Xu JP, Li YC, Lai J, Li Q (2009) Pulmonary myopericytoma: A case report and review of the literatures. Chin Med J (Engl) 122: 755-757.

69. Mentzel T, Dei Tos AP, Sapi Z, Kutzner H (2006) Myopericytoma of skin and soft tissues: Clinicopathologic and immunohistochemical study of 54 cases. Am J Surg Pathol 30: 104-113.

70. Scott RS, Blank KL, Proffer LH, Kraus EW, Heim-Hall J (2006) Perivascula myoma of myopericytoma and myofibromatosis-type arising in a chronic scar. J Cutan Pathol 33: 231-235.

71. Toh HC, Teo M, Ong KW, Lee V, Chan E, et al. (2006) Use of sirolimus for Epstein-Barr virus-positive smooth-muscle tumour. Lancet Oncol 7: 955-957. 